\title{
RE-EXAMINING THE EXAM: SOCIAL PSYCHOLOGICAL PERSPECTIVES ON STANDARDIZED TESTING IN INDIA
}

\author{
Merayah Sardana \\ Vasant Valley School New Delhi \\ DOI: 10.46609/IJSSER.2020.v05i09.016 URL: https://doi.org/10.46609/IJSSER.2020.v05i09.016
}

\begin{abstract}
Why re-examine the exam? Is there a fundamental flaw with standardized testing, or does it fall prey to the same equity-equality, liberty-equality, and diversity-equality dilemmas that have plagued scholars, philosophers, and citizens for decades? Taking social and educational psychological perspectives on standardized testing in India, specifically focused on standardized testing at the school levels, can thus provide an important lens in not only revisiting the ways in which such testing excludes key areas of the populations, but also affects the ways in which millions of young students understanding and process the very idea of 'intelligence' and selfworth. Beyond socio-economic consequences, this essay argues thus that there exist personal and political consequences to the large scale incidence of standardized testing in schools across India, limiting notions of progress and growth to those that are limited to capitalist, colonial-era metrics of productivity, rationality, and growth in terms of magnitude. The essay also considers alternatives to existing patterns of standardized testing that can be implemented in a manner that is cognizant of cultural, economic, and sociopolitical realities, and also in a manner that does not add excessive strain to teachers and other individuals employed for the execution of such forms of assessment, teaching, and learning-enablement in the country.
\end{abstract}

Keywords: Education, Exam, Population, Testing, Student.

\section{Introduction}

Why re-examine the exam? Is there a fundamental flaw with standardized testing, or does it fall prey to the same equity-equality, liberty-equality, and diversity-equality dilemmas that have plagued scholars, philosophers, and citizens for decades? Taking social and educational psychological perspectives on standardized testing in India, specifically focused on standardized testing at the school levels, can thus provide an important lens in not only revisiting the ways in which such testing excludes key areas of the populations, but also affects the ways in which millions of young students understanding and process the very idea of 'intelligence' and self- 


\section{International Journal of Social Science and Economic Research}

ISSN: $2455-8834$

Volume:05, Issue:09 "September 2020"

worth. Beyond socio-economic consequences, this essay argues thus that there exist personal and political consequences to the large scale incidence of standardized testing in schools across India, limiting notions of progress and growth to those that are limited to capitalist, colonial-era metrics of productivity, rationality, and growth in terms of magnitude.

Thus, the essay also considers alternatives to existing patterns of standardized testing that can be implemented in a manner that is cognizant of cultural, economic, and sociopolitical realities, and also in a manner that does not add excessive strain to teachers and other individuals employed for the execution of such forms of assessment, teaching, and learning-enablement in the country (Salaky, 2018). The article begins by analyzing the growth of educational psychology as a field that has moved beyond monolithic understandings of learning improvements, to a paradigm of non-hierarchical, poststructuralists, and feminist considerations of inclusive learning that aren't simply, as some say, providing consolation prizes and participation certificates to all those who exist, but pursue a more pluralistic mode of understanding skills and intelligence, taking into consideration more recent developments in the disciplines of psychology, neuroscience, sociology, and education (Forehand, 2010).

The paper considers close likenesses in other disciplines to the 'student' and 'teacher' characterisation, including those such as international law, political science, subaltern studies, philosophy, and literature. It then moves on the outline the evolution and emergence of new theories including Gardner's "Theory of Multiple Intelligences" which have played a significant role in improving our understanding of how standardized testing not only includes a large number of persons with disabilities, but operates of a objectified, mechanized understanding of human productivity that doesn't account for variations in physical and mental health, gendered barriers (including menstruation), and more (Gardner, 1989).

The paper thus ultimately attempts to reimagine the examination in the Indian context, to invert the gaze of the assessors onto themselves, to perform a form of self-critique using social psychological lenses, to better understand ways in which such systems can develop and evolve in the years to come. This is particularly relevant in consideration of the new draft National Education Policy proposed in India, which has already faced severe criticism for being classist and casteist in nature (Salaky, 2018). While not deeply perusing this, it posits the same as a matter for consideration, both for present and future students in the country's large and complex education system.

\section{Background}

Educational psychology, as a discipline, has grown over the course of the past years to incorporate critical insights from cognitive, behavioral, developmental, and adolescent 


\section{International Journal of Social Science and Economic Research}

ISSN: $2455-8834$

Volume:05, Issue:09 "September 2020"

psychology. Furthermore, these insights have been tailored to specific cultural and social contexts, including different modes of teaching, learning, language and knowledge processing, retention, and expression (Salaky, 2018). Even long standing structures of seemingly critical education theory, such as Bloom's taxonomy (revised in 2011 by his colleagues for a structure, moving from the bottom of the pyramid to the top, of remember-understand-apply -analyze evaluate--create), has found valid criticism in terms of an ineffective and homogenized hierarchization of knowledge processes, unmindful of context -- whether it be disciplinary context, cultural context, identity context, or the type of information considered (Forehand, 2010). Besides this, education in itself, with respect to teaching and learning, has gone past the "banking system" so characterized by Paulo Freire in his 'Pedagogy of the Oppressed', laying praise to the Socratic method in a manner that is akin to a comparison of student to the unspoken, silent subaltern characterized by Gayatri Spivak in 'Can the Subaltern Speak', or Makau Mutua's "victim" in the savage-victim-savior trilemma (Spivak, 2003; Mutua, 2001).

In this context, multiple theories of intelligence as have progressed with time are to be considered and education systems must be evolved in order to meet these evolving understandings (Gardner, 1989). This, therefore, primarily presumes that academic scholarship is accessible and, for the most part, popularly agreed upon to an extent such that it reaches the ears of those individuals responsible for a state's education policies. In most countries, particularly democratic countries, this may not be an accurate or sound presumption to begin with in the first place (Salaky, 2018). However, for the sake of theorization, to move forward one would from a normative standpoint propound that evolving theories of intelligence must be considered in the framing of national education policy in its different dimensions -- teaching, learning, and of course, assessment. It is here that standardized testing comes into particular play. Theories such as Howard Gardner's "Theory of Multiple Intelligences" argued for an understanding of intelligence that is, in many ways, a poststructuralist understanding -- to consider the dynamic diversity of intelligence, from musical and artistic forms, to analytical and mathematical forms (Gardner, 1989).

In the Indian context, as previously mentioned, there exists an intensive testing culture that is, for the most part, unmindful of these evolutions in research and understanding, and similarly unmindful of the need to evolve in an inclusive perspective. At the school level, examinations are conducted following curriculums set by the Central Board of Secondary Education, government by Ministry of Human Resource Development, which also provides guidelines for examinations which rely, for the most part, on rote learning, memorization, pre-preparation via the remembrance of questions from past examinations, and so on, thereby providing little room for the more diverse and inclusive forms of memory, cognition, and knowledge processing that one prioritizes at the highest level during undergraduate and graduate study, particularly with the 


\section{International Journal of Social Science and Economic Research}

ISSN: 2455-8834

Volume:05, Issue:09 "September 2020"

humanities and social sciences (Salaky, 2018). This, combined with a human resource crisis in the education sector that makes reforms even more untenable, results in a large number of unemployable youth graduating school each year.

\section{Discussion}

Standardized testing, due to its singular and unidimensional propagation of particular methods of learning, thus results in not only the lack of prioritization of certain types of intelligences, but also results in 'merit' being defined in extremely limited terms, thereby shaping the kinds of knowledge processing techniques employed by these students from a very young age. The Socratic method is a far distant dream for the student even in the most elite of private schools in the Indian metropolitan city, where there is a common consensus and destruction of the ability to provide retort, disagree with the teacher -- who is in every manner placed on a pedestal where his or her (mentioned in binary terms to intentionally highlight the severe lack of non-binary teaching staff in India) knowledge is considered sacred, to question is sacrilege, and the method in which they provide said information is the only method in which it must be remembered, and therefore reproduced (Salaky, 2018).

From a social psychological perspective, there are a variety of consequences that can be drawn from the large scale existence of standardized testing as the only form of testing known by Indian students -- who number in the millions. This could include a mass incidence of self-serving bias, where students are led to believe that only said and specific kinds of knowledge would be tested, and anything not conforming to the same is not constitutive of intelligence (McAllister, 1996). This, arguable, is represented in the present levels of output and productivity -- wherein an intersectional perspective is required to understand how a large number of young people from middle- and upper-class backgrounds tends to take up careers and find excellence in fields broadly within the arts and humanities, while those from lower caste and class backgrounds often find themselves in STEM and managerial fields, and as previously mentioned, without the requisite skill-set to be effectively employable (Salaky, 2018). Considering the self-concept, standardized testing in the Indian context also results in a scenario where students possess skewed self-perception in terms of affect, behavior, and cognition, and similarly skewed understandings of real-world conditions, thus facing a greater psychological difficulty in adjusting to a world that does not run according to, prioritize, or give extreme importance to such forms of rote learning and memory (Purkey \& Novak, 1996).

The arrival of technological developments has only served a role of exacerbating this condition, as the skills even to some extent focused upon, such as improving one's memory, have found lesser importance with the ability to find information at a moment's notice, with a few clicks. There is thus a need to consider effective alternatives to existing educational and testing 


\section{International Journal of Social Science and Economic Research}

ISSN: $2455-8834$

Volume:05, Issue:09 "September 2020"

frameworks in India, in a manner that is cognizant not only of the aforementioned considerations in educational and social psychology, but also effectively aware of process limitations, institutional barriers, and ground level realities often not reflected in either official statistics or dominant academic or policy discourse.

Alternatives to existing systems could include lesser importance given to merely written final examinations that are considered the primary forms of assessment, and greater importance given to a form of holistic assessment that is done in a continuous manner throughout the course of the year. This could include, inexhaustive, particular skill sets that students are able to acquire -whether it be in the Arts, via independent research, co-scholastic endeavors, sports, and more. At higher levels, such as high-school and beyond, students can be offered choices between interview-based, written, and presented methods of showcasing their understanding of subjects. Take-home examinations, which offer students the opportunity to flexibly use time and their resource, are another very practical alternative, requiring little to no changes in the existing manpower required in the educational sector, and further being progressive in considering collaborative efforts, research, and study not as 'cheating' or insincere or lacking in skill, but as efficient processes and skills valuable to the life of any student, teacher, and individual.

\section{Conclusion}

The paper has thus considered social psychological approaches, including theories of the self, schema, and self-serving bias to be considered as potential consequences of the standardized testing which millions of students participate in on a monthly basis in India. It provides a roadmap by suggesting possible alternatives to this form of assessment, in forms that would add no excess burden on the monetary and other resource constraints plaguing existing systems.

It is thus important to consider the originally provided caveat of critical psychological and theoretical scholarship not being presented in accessible forms for policy-makers, teachers, students, and other key stakeholders within the Indian education systems (and also other education systems across the world). It also stresses the need for better funding, resource and budget allocation for the purposes of revamping India's education infrastructure in a manner that can reflect better, more diverse, and more inclusive teaching and learning practices that can pave the way for creating a more inclusive, sustainable, socially responsible, and diverse populace in the years and decades to come.

\section{Bibliography}

Forehand, Mary. "Bloom's taxonomy." Emerging perspectives on learning, teaching, and technology 41.4 (2010): 47-56. 
International Journal of Social Science and Economic Research

ISSN: 2455-8834

Volume:05, Issue:09 "September 2020"

Gardner, Howard, and Thomas Hatch. "Educational implications of the theory of multiple intelligences." Educational researcher 18.8 (1989): 4-10.

McAllister, Hunter A. "Self-serving bias in the classroom: Who shows it? Who knows it?." Journal of Educational Psychology 88.1 (1996): 123.

Mutua, Makau. "Savages, victims, and saviors: The metaphor of human rights." Harv. Int'l LJ 42 (2001): 201.

Purkey, William Watson, and John M. Novak. Inviting school success: A self-concept approach to teaching, learning, and democratic practice. Wadsworth, Inc., Distribution Center, 7625 Empire Drive, Florence, KY 41042-2978., 1996.

Salaky, K. "What standardized tests look like in 10 places around the world." Insider (2018).

Spivak, Gayatri Chakravorty. "Can the subaltern speak?." Die Philosophin 14.27 (2003): 42-58. 